\title{
On the interaction of physics with science education research
}

\author{
Peter W. Hewson \\ Department of Curriculum \& Instruction, University of Wisconsin-Madison, 225 North Mills Street, Madison, WI, 53706
}

\begin{abstract}
In the decade after completing my doctoral degree in theoretical nuclear physics, my professional interests changed from how elementary particles interact with nuclei to how students learn physics. To use an optical metaphor, my physics lenses helped me focus on some aspects of how students learn the discipline of physics. Identifying isolated systems, looking for causal mechanisms, and adapting models of interactions are examples of physics approaches that guided my journey of understanding this new field. Yet my physics lenses left other aspects out of focus and even out of my field of view. To notice and pay attention to these aspects, I needed other lenses. Examples of these are the philosophy of education with respect to teaching and learning, the history of science with respect to how disciplines advance, and cognitive psychology with respect to the role of students' knowledge in learning. I use my own experiences in moving from physics into the practice of science education to illustrate the interaction of physics with science education research.
\end{abstract}

\section{PROLOGUE}

I started out in physics: after a doctorate from Oxford University and a post-doctorate fellowship at the University of British Columbia, I joined the physics department at the University of the Witwatersrand in 1971. While there, I took on responsibility for educating physics teachers, eventually concluding that I was a science educator rather than a physicist. In 1985 I moved into the School of Education at the University of Wisconsin-Madison. I draw from my own experiences in these settings to identify where my physics background contributed and where I needed to go beyond it. I do so by looking at three cases that illustrate different aspects of my professional journey.

\section{CASE 1: WORLDVIEW COMPATIBILITY}

The first case poses the question: What did a physics worldview contribute to my understanding of student learning?

\section{A. Physics 1}

I begin with an article based on my doctorate in theoretical nuclear physics entitled "Charge exchange in nuclei following pion inelastic scattering"[1], focusing on the process I went through as a graduate student rather than the content. The process started with a problem: existing theory could not explain an experimental result. A theoretical model was proposed, and calculations determined its effects. The result was that the model reduced the discrepancy between theory and experiment. I assume the steps I went through are well known to all of you.

My doctoral study illustrates what I mean by a physics worldview. The study postulated a model of an individual pion scattering off a carbon nucleus, based on an assumption that it was an isolable system: what happened within the system was sufficiently important that what happened outside could be ignored. The model specified reactions that were illuminated in representations of different sorts, such as diagrams, mathematics and computation. Other things were embedded in that work. One was generalizability: while the model was about an individual pion and nucleus, it could be generalized to an experiment conducted with a macroscopic beam of pions on a physical target containing countless nucleons. Cause and effect was another component of this physics worldview, and there was a clear relationship between experiment and theory. Finally, the article constituted a rational argument based entirely on its physics, as illustrated by its exclusive use of the third person in its language.

\section{B. Education 1}

The question that interested me in the decade after my doctorate was: How do students learn complex structured content, such as physics?

The dominant paradigm for education research at that time was a quantitative, experimental approach. An example is an article by Jon Wooley entitled "Factors affecting students' attitudes and achievement in an astronomy computer-assisted instruction program" [2]. The steps involved were: identify variables, develop an intervention, use experimental and control groups, gather pre-and post-data, and analyze with inferential statistics. Such an approach allows researchers to make empirical generalizations: the expectation is that if they use the same intervention with a different group of students, presumably like the ones in that study, they can expect similar results. One thing to note about this study is that it collected no data about the instructional intervention between pre- and post-data collections: the assumption is that the intervention worked as intended.

Another research approach was, however, gaining traction at that time. Illustrating this qualitative trend is a paper by John Clement entitled "Students' preconceptions in introductory mechanics" [3]. Clement used "written tests and videotaped problem-solving interviews" with students to analyze the content of their conceptions. The conclusion he reached was that a misconception many held "is highly resis- 
tant to change and is remarkably similar to one discussed by Galileo." One outcome of research of this kind is to affirm the significance of the process when students are thinking about ideas and problems. This leads to a theoretical generalization: the article provides evidence that students are active learners, they can develop arguments and can give reasons to support their conclusions (albeit not always those that we as physicists would expect). In other words, they are rational. It is not, however, a claim that because one group of students holds a particular misconception, it would necessarily be the same in larger or different groups. Nevertheless the evidence shows that the possibility exists, with the implication that it is something other researchers need to explore. A more general point is that constructivism was seen as a powerful way of thinking about outcomes such as the identification of student misconceptions.

I draw two conclusions from this case. First, my physicsinfluenced worldview has a close affinity with constructivism. It doesn't mean that all aspects transfer completely because there are differences between physics and education. While we are all humans in this room, there are variations for every human trait. So in education, individual differences mean we can't simply assume generalizability as we do in the physics world.

A second conclusion concerns teaching and learning. A plausible assumption is that cause and effect link the two: I teach, therefore people learn. While there is a relationship between the two, it is not causal, but ontological: it is in their very nature that teaching and learning are related, even if teaching does not always lead to learning. A good way is to think that teaching facilitates learning.

\section{CASE 2: CONTRIBUTION OF AN ANALOGY}

The second case considers how an analogy drawn from physics has influenced education. It poses the question: Is student learning analogous to the growth of disciplinary knowledge?

\section{A. Physics 2}

If we think about the growth of science, we frequently start with Isaac Newton's statement: "If I have seen further than others, it is by standing on the shoulders of giants." This image of the progress of science is an ever-upward view, a construction view, a building view. A modern image comes from water skiing in which teams of skiers build human pyramids by climbing on one another's shoulders.

In 1905 Albert Einstein wrote an article that posed a problem for this view of how science progresses [4]. In proposing the Special Theory of Relativity, Einstein started with an anomaly. He was interested in electromagnetic inductionthe production of an electric current when a coil and a magnet move relative to another. He noted that if we consider the coil to be at rest, we have a changing magnetic field and there are explanations for that. If, on the other hand, we consider the magnet to be at rest we have a changing electric field and there were theories to explain that. But what concerned Einstein was that these were different explanations. This contradicted his epistemology: if we have the same phenomenon we should not have different theories. The theory he developed provided the same explanation for both phenomena. He based it on two principles, first, the principle of relativitythere is no such thing as an absolute frame of reference-and second, the speed of light is constant regardless of the frame of reference. In particular, it has other counter-intuitive outcomes that are well known to us: moving rods get shorter, and moving clocks run slower.

Thomas Kuhn's book, The Structure of Scientific Revolutions, published in 1962, postulated different ways of thinking about how science progresses [5]. Kuhn's doctorate was in physics; he then became interested in why scientific theories are either accepted or rejected. He concluded that there are two types of science: Normal Science-a puzzle-solving activity conducted under a reigning paradigm. My doctoral dissertation is clearly an example of this. And then Revolutionary Science - an anomaly creates a crisis that leads to a paradigm shift. Einstein's article is an excellent example of revolutionary science.

\section{B. Education 2}

This, then, leads to the question with which I started: Is student learning analogous to the growth of disciplinary knowledge? The pursuit of this question led to an article entitled "Accommodation of a scientific conception: Toward a theory of conceptual change" [6]. On sabbatical at Cornell University, I collaborated with George Posner, a curriculum specialist with a degree in physics, Ken Strike, an educational philosopher, and Bill Gertzog, a graduate student working on the project. The article did two things.

First, we looked at the conditions of conceptual change. Drawing from the history and philosophy of science, we identified four different conditions under which conceptual change might happen. While they aren't necessarily complete, they were productive in helping us think about conceptual change. The first condition-dissatisfaction-has the effect of lowering the status of current ideas [7]. If we subscribe to a well-established theory, there have to be good reasons for considering competing ideas seriously. The other three conditions contribute to raising the status of new ideas. The first of these is intelligibility. We can't consider anything if we don't understand what it is. Intelligibility means that we can give it meaning and we can understand its content. The second is plausibility. When we say moving clocks run slower, that's intelligible; whether we believe that's the case, however, whether we are convinced that's the way the world works, whether it fits with other things we know is a question of plausibility. Engaging with plausibility involves 
being metacognitive about our own knowledge: to look at it and ask how it fits with other things we know. Finally, fruitfulness is a condition that gives reasons to carry on with a new idea. Does it solve other problems? Does it suggest new approaches? The fruitfulness of Einstein's special theory of relativity has been reconfirmed, not for the first time, with the recent discovery of gravity waves.

Second, we reported on an empirical study to investigate student understanding. Could we find evidence in interviews that students considered the conditions of conceptual change? I was teaching a tutorial section in a freshman non-major physics course at Cornell. Since it was a mastery-learning course there were frequent opportunities for me to talk to students as they completed each unit in progressing through the course. The course included a unit on special relativity that considered the issues at the heart of Einstein's article. I interviewed students in my section (an available sample). The interview was structured to find out how students understood special relativity. How did they make sense of it? Did they find it intelligible? What about its plausibility? Was it fruitful or useful to them?

We undertook the study to address the question: Is student learning analogous to the growth of disciplinary knowledge? In other words, do students see anomalies? Do students have commitments about the nature of knowledge, and principles about the natural world? Do students change their minds for rational reasons? As we started the study, we were somewhat skeptical that this would be the case. The outcomes, however, convinced us to answer all these questions in the affirmative; posters at this conference have reassured me that this is still the case.

Let me give you one example from the paper about a commitment to absolute space and time. CP was a student who struggled in the early parts of the course, particularly with force and motion. She was not the first to find that difficult, but she persevered with me until she figured it out, and brought a new self-confidence to other units and, eventually, relativity. As we looked at some of its implications, the following conversation ensued:

CP: Yeah, I mean, absolute time it just seems to go on at a certain rate everywhere. It just seems natural that it's constant everywhere. I mean, even though you see these results.

I: It seems these are strange results. What attitude do you take of these results?

CP: I say they don't really mean all that much; it just depends on what your frame is. It's sort of like potential energy depends on the way you define zero to be?

I: The amount of potential energy you've got?

CP: Right, all relative to what's going on. [6, p.219]

She rationalized why she was not prepared to believe time dilation — she found it intelligible, but not plausible — and she had a reason for doing so. While we can, of course, criticize her conclusion, she reasoned with something she learned in this course about potential energy, as well as interpreting relativity in a different way. She was, in addition, willing to think and talk about her reasoning.

So the analogy between physics and education has been productive. It influenced my understanding of the types of intellectual work that students can and do engage in. Personally, the theory of learning as conceptual change launched my career in science education and led me to studies of teaching, teacher education, and professional development. The article has been cited more than 5,500 times and counting: it clearly struck a nerve in science education and beyond.

\section{CASE 3: WORLDVIEW CONTRAST}

The final case considers the question: Why are methods of research treated so differently in physics and education?

\section{A. Physics 3}

Consider my doctoral thesis: its research design consisted of problem posing, model construction, calculation of model effects, and comparison with previous theoretical results to produce a final result. As I suggested, it's a design that none of you would find controversial or difficult. So it may not be surprising that in the course of my graduate study there was no formal course work on research design and methodsthere didn't seem to be any need for it.

\section{B. Education 3}

In contrast, my experiences in the world of education were different. My introduction came when I was a postdoctoral fellow at the University of British Columbia. A visiting professor in physics and two professors in science education collaborated on a project-Physics Education Evaluation Project-to investigate a first-year non-major physics course. Project personnel gathered data in many different ways: they made observations of teaching in lectures, tutorials (including one I was teaching), and labs; they conducted interviews with teachers and students about various aspects of the course; and they collected test scores and questionnaire responses.

Another example comes from my experience as a faculty member in science education at the University of WisconsinMadison. The graduate curriculum in the department requires coursework on research design, and on a broad array of different research methods, e.g., statistical, qualitative, narrative. In designing research, a doctoral candidate selects from this array, but with the constraint that all components need to be coherent with each other. Thus a typical dissertation includes chapters on theoretical frameworks, a literature review, and research methods before the data is presented and analyzed, and conclusions drawn. In other words, these chapters present arguments to support the coherency of the dis- 
sertation's research design. These address why the research questions were chosen, what data were gathered and how they were analyzed in order to answer them.

In summary, since there are many ways of gathering data in educational research, the selection of methods and the design of coherent research need explicit attention.

Why are methods of research treated so differently in physics and education? I see contributions from three aspects of these disciplines.

\section{Objects of Study}

With respect to physics, the objects of study come from the natural world. Physicists tend to look at these things in the simplest possible way: when they look at a tree, they see an object with distributed mass that is able to resist particular sorts of stresses and strains and support particular types of loads. The value of taking a simple view such as this is that it allows physicists to handle it in sophisticated, complicated, and powerful ways. This, to me, is one reason why physics is the first of the sciences, because it looks at simple systems and handles them in ways that become increasingly complex. There is also an assumption of universality about what physicists study-regardless of whether an experiment is carried out in Sacramento, Santiago, or Saigon, we expect to get precisely the same result.

In contrast, the objects of study in education are humans and human systems, and we know that we are complex in many different sorts of ways: we can be rational or irrational; we have emotions and motivations as well as the power of cognitive thought. There are individual differences across human populations. Also, humans respond to their environment, and do so in different ways at different times: their responses are tempered by context, culture, and complexity in all sorts of ways.

\section{Nature of Discipline}

A second aspect is that the knowledge domains in these two worlds are very different. Knowledge in physics is extremely complicated, sophisticated, and coherent. Its components are tightly connected: if we make a change in one place we expect to see implications elsewhere. Its architecture has a lengthy history that is well established. A consequence-and this is my hypothesis - is that there is less reflection about its deep roots than in education.

In contrast, education as a discipline is much more recent. It is very broad, it is multi-layered, and-no surprisemultiple perspectives, components and contexts are present. In addition, educational systems and the humans who populate them are loosely connected: one can push on one part of such a system and not be surprised if it fails to have much influence elsewhere. As a consequence-the other side of my hypothesis-education needs much more reflection on its theoretical roots if it is to make new knowledge that is well based and cogently argued.

\section{E. Community}

A final aspect contributing to differences in how research methodology is handled is community. Simply because of its nature, physics is much more likely to have a higher consensus within and between its communities of sub-disciplines, and, as a result, it is more difficult to push on its boundaries. In education it is somewhat different, because there are multiple communities, with the likelihood of less consensus across communities. Thus it is easier to push against and across boundaries, to move into new areas and try different approaches.

\section{EPILOGUE}

These cases illuminate how physics contributed to my understanding of teaching and learning physics. Case 1 documents a physics schema that helped me think about learning physics as an active enterprise: namely, as individual constructivism. Case 2-the analogy between physics and learning-helped me affirm that students can and do reason with varied types of knowledge. This is important and powerful and needs to be taken into consideration in teaching. Case 3 builds an argument, based on differences in how research methods are handled, that physics research methods only go so far in education. Other approaches are needed to pay attention to the complexities of research with humans. These demonstrate that social interactions within communities facilitate physics learning and the value students accord it. This leads into different theories such as social constructivism and critical theory that guide us in understanding whether educational systems are doing what we really want them to do. This perspective leads me to look at the learning of physics as something that students have to do for themselves, thereby making the physics their own. Physics is not just knowledge that was generated by dead white guys, but knowledge that is relevant to us right now. For this to be the case, our social settings, the people we interact with, the communities in which we are involved, and local and national debates all play critical roles.

When I told the head of my department in Johannesburg before my sabbatical in 1977 that I was going to study education, Frank Nabarro, an eminent solid-state physicist, said, "Physics problems are straightforward, self contained, well defined, and solvable." He continued, "Education problems, in contrast, are complex, sprawling, ill defined and difficult to solve." And he concluded, "But education problems are probably more important." I agree with him. 
[1] Peter W. Hewson, "Charge exchange in nuclei following pion inelastic scattering," Nuclear Physics A 133, 659-672 (1969).

[2] Jon K. Wooley, "Factors affecting students' attitudes and achievement in an astronomy computer-assisted instruction program," Journal of Research in Science Teaching 15, 173-178 (1978).

[3] John Clement, "Students' preconceptions in introductory mechanics," American Journal of Physics 50, 66-71 (1982).

[4] Albert Einstein, "On the electrodynamics of moving bodies,"
Annalen der Physik 17, 891-921 (1905).

[5] Thomas S. Kuhn, The Structure of Scientific Revolutions (University of Chicago Press, 1962).

[6] George J. Posner, Kenneth A. Strike, Peter W. Hewson, and William A. Gertzog, "Accommodation of a scientific conception: Toward a theory of conceptual change," Science Education 66, 211-227 (1982).

[7] Peter W. Hewson, "A conceptual change approach to learning science," European Journal of Science Education 3, 383-396 (1981). 